\title{
DNA Markers RM 464A and RM 219 Haplotypes are Effective in Selecting Sub-1 locus for the Introgression of Submergence Tolerance into New Rice Varieties
}

\author{
N. R. M. K. N. D. Rathnayake ${ }^{1}$, A. P. Bentota ${ }^{2}$, D. M. N. Dissanayake ${ }^{3}$, K. L. N. S. Perera ${ }^{4}$, \\ S. D. S. S. Sooriyapathirana ${ }^{5}$, G. A. U. Jayasekera ${ }^{1} *$ \\ ${ }^{1}$.Department of Plant Sciences, University of Colombo, Colombo 03, Sri Lanka. \\ ${ }^{2}$ Regional Rice Research and Development Centre, Bombuwela, Kalutara, Sri Lanka. \\ ${ }^{3}$ Rice Research and Development Institute, Bathalagoda, Ibbagamuwa, Kurunegala, Sri Lanka. \\ ${ }^{4}$ Genetech Molecular Diagnostics and School of Gene Technology, Colombo 08, Sri Lanka. \\ ${ }^{5}$ Department of Molecular Biology and Biotechnology, University of Peradeniya, Peradeniya, Sri Lanka. \\ Accepted 06 December 2012
}

\begin{abstract}
Incorporation of submergence tolerance, controlled by $S u b-1$ locus, into local rice varieties was attempted by using DNA marker assisted breeding. Submergence tolerance among tested rice varieties was accurately phenotyped by evaluating acclimative shoot response. Submergence intolerant varieties displayed greater shoot elongation while submergence tolerant plants showed restricted elongation during submergence. During de-submergence all susceptible varieties withered and perished while tolerant plants showed nearly $100 \%$ survival and they were assigned the survival score of 1. Microsatellite DNA markers RM 464A and RM 219 that are linked to $S u b-1$ were used to genetically screen for $S u b-1$ locus. Two alleles (226 and 231 bp) of RM 464A marker were detected among the tested varieties. All the tested varieties displayed $226 \mathrm{bp}$ allele of RM 464A with the exception of variety Bw 363 (231 bp). Higher allelic variability (190, 214, 220 and $230 \mathrm{bp)}$ for RM 219 marker was observed. The polymorphism detected for RM 464A and RM 219 between varieties IRRI 119 ( $\mathrm{Sub}$-1 donor) and Bw 363 has allowed us to identify specific alleles of the two markers. The haplotype of $226 \mathrm{bp}$ allele of RM 464A and $220 \mathrm{bp}$ allele of RM 219 were used as diagnostic alleles or gel bands to monitor Sub-1 in IRRI $119 \times$ Bw 363 cross. Easily-scorable bands for these two markers accurately and reliably distinguished submergence tolerant plants in a $F_{2}$ population. These results demonstrated that the two studied DNA markers can be used to introgress $S u b-1$ locus into local rice varieties to achieve submergence tolerance.
\end{abstract}

Keywords: Sub-1 locus, submergence tolerance, DNA markers, marker assisted selection

\section{INTRODUCTION}

Rice (Oryza sativa L.) is the staple food for more than half of the world's population (Jena and Mackill, 2008). The plant is normally semiaquatic and is well adapted to survive in partially flooded conditions (Fukao and Serres, 2008). However, flash flooding which takes place during the monsoon season is a serious problem for rice production in the rainfed lowlands of South and Southeast Asia. Nearly 50\% of the rice growing land in the region is affected by flash flooding at various stages of growth (Toojinda et al., 2003). In this context, having submergence tolerant rice varieties is very important in minimizing flood damages in rice production.

Both iron toxicity and submergence are two major environmental problems prevalent in the
Western Province of Sri Lanka that hamper rice productivity in this region. It has been reported that the floods in Ampara, Polonnaruwa, Anuradhapura and Batticaloa districts during December 2010 to January 2011 were very destructive and nearly $90 \%$ of 'Maha' season rice crop (approximately 450,000 tons) in these districts has been destroyed (FAO country report, 2011).

During submergence, tolerant rice plants exhibit inhibition of shoot elongation, retain chlorophyll in leaf tissues and maintain viability. However, submergence intolerant plants show drastic shoot elongation and become chlorotic during submergence. When water levels subside, submergence tolerant rice plants restart growth by elongating existing shoots and developing new shoots whereas submergence intolerant plants simply die. These responses in shoot

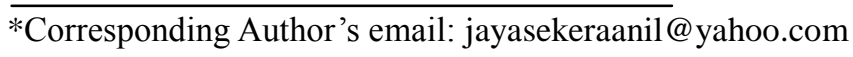


growth in submergence tolerant and intolerant rice plants are collectively known as acclimative shoot response.

The submergence tolerant landraces such as flood resistant 13A (FR13A) and FR43B from Orissa, India and Kurkaruppan, Goda heenati, and Thavalu from Sri Lanka were recognized for their resilience to complete submergence (Setter et al., 1997; Serres et al., 2010). FR13A can endure compete submergence for 2 weeks or longer (Fukao et al., 2008). However, submergence tolerant landraces lack important agronomic attributes (Xu et al., 2004). The submergence response is regulated by the Submergence-1 (Sub-1), a major Quantitative Trait Locus (QTL) which is responsible for $70 \%$ of phenotypic variation in submergence tolerance and, has been fine mapped on Chromosome 9 of rice genome (Xu and Mackill, 1996). Sub-1 is reported to be a polygenic locus encoding three putative ethylene-responsive factor (ERF) DNA binding proteins. All Oryza sativa accessions encode SublB and SublC at this locus. An additional ERF SublA has been identified and its presence is reported to be variable. All analyzed $O$. sativa ssp. japonica varieties lack SublA. However, SublA is identified in two allele forms: SublA-1 and SublA-2 in O. sativa ssp. indica varieties (Xu et al., 2006). SublA-1 is found only in submergence tolerant lines such as FR13A whereas SublA-2 allele is present in intolerant $O$. sativa ssp. indica accessions (Xu et al.,
2006).

Conventionally, plant breeders select plants based on the phenotype which is generally represented by the visible and measurable traits of plants. However, phenotyping for submergence tolerance in rice is a cumbersome process since it involves submerging rice plants in water for 10-14 days. The expression of the genes for submergence tolerance is also environmentally dependent (Toojinda et al., 2003) and therefore, accurate phenotyping is not easy, making conventional breeding for submergence tolerance an inaccurate and inefficient endeavor. However, DNA based markers that are tightly linked to the submergence QTLs can be used to circumvent the problem associated with conventional breeding for submergence tolerance and to release varieties with a higher level of confidence and more rapidly. Codominant PCRbased markers, such as microsatellite markers, would be ideal for the selection for submergence tolerance in breeding programs. Two DNA microsatellite markers, RM 219 and RM 464A have been mapped to the $S u b-1$ locus (Figure 1). RM 219 is $3.4 \mathrm{cM}$ and RM 464A is $0.7 \mathrm{cM}$ away from the Sub-1 locus (Xu et al., 2004). In a subsequent study based on fine mapping of $S u b$ 1 locus and O. sativa var. japonica Nipponbare sequence information, the physical distance of RM 464A and RM 219 to Sub- 1 has been determined to be $0.2 \mathrm{Mb}$ and $1.5 \mathrm{Mb}$ respectively (Neeraja et al., 2007).

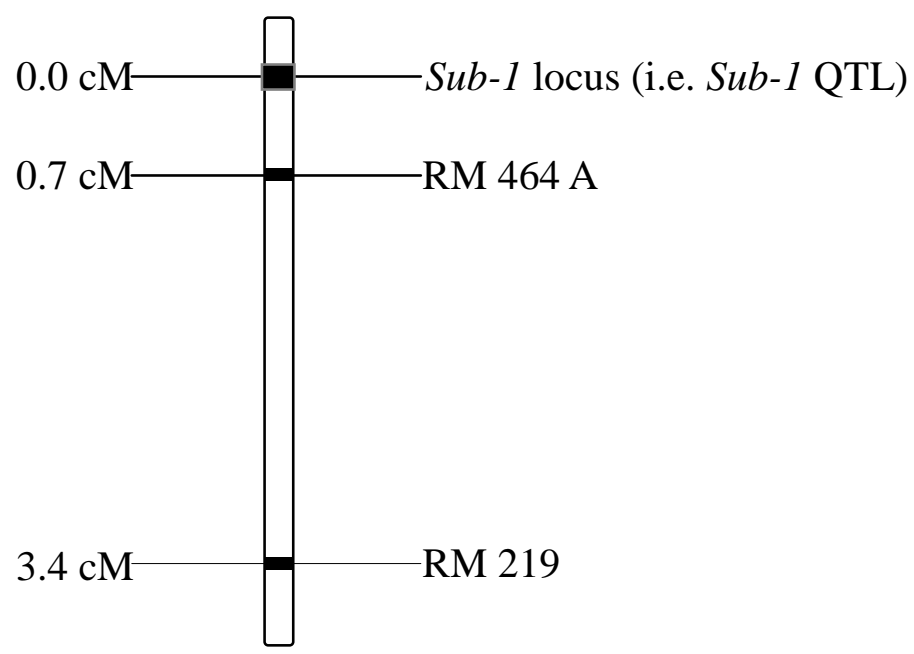

Figure 1. Map positions of Sub-1 locus and two linked DNA markers (RM 464A and RM 219) used in the present study. These loci are located on Chromosome 9 of the rice genome and only the relevant portion is illustrated. Relative cM distances are shown on the left and QTL and loci names are shown on the right. In the rice genome map of Chromosome 9, the loci Sub-1, RM 464 A and RM 219 are located at the physical positions of 6.3 Mb, 6.5 Mb and 7.8 Mb respectively (Xu et al., 2004; Neeraja et al., 2007). 
These two DNA markers have been previously identified as useful markers, for selection of submergence tolerance controlled by $S u b-1$ in a rice breeding programme (Xu et al., 2004).

DNA Marker Assisted Selection (MAS) in plant breeding, greatly increases the efficiency and precision of varietal improvement. MAS is also known as 'molecular breeding' (Collard and Mackill, 2008) and this represents one of the two modern paradigms of improving plants or animals for agricultural purposes. Recently, Sub1 was successfully introgressed into several Asian rice mega varieties; Swarna, IR64, Samba Mahsuri, Thadokkham1 (TDK1), BR11, and CR1009 (IRRI, 2007) following a marker assisted back crossing strategy. According to our knowledge, the same approach can be used to improve the popular Sri Lankan rice varieties for submergence tolerance but no attempts have been made so far.

The main objective of the present study was to implement DNA marker assisted breeding to incorporate submergence tolerance trait controlled by $S u b-1$, reported major QTL for submergence tolerance, into a locally adapted rice variety $\mathrm{Bw} 363$.

\section{MATERIALS AND METHODS}

\section{Plant materials}

Three submergence tolerant enhanced mega varieties (Swarna-Sub-1, IR64-Sub-1 and Samba Mashuri-Sub-1), IRRI 119 (a Sub-1 containing variety released as PSB Rc68 in Philippines), Goda heenati a known submergence tolerant local traditional variety) and three submergence intolerant local varieties (Bg 360, Bg 94-1 and $\mathrm{Bw}$ 363) were used for submergence screening and DNA marker analysis. Seeds of these varieties were obtained from Regional Agricultural Rice and Development Center (RARDC), Bombuwela, Sri Lanka and Rice Research and Development Institute (RRDI), Bathalagoda, Sri Lanka.

All $S u b-1$ containing varieties were developed at IRRI, Los Banos, Philippines. IRRI 119 was used as the $S u b-1$ donor in the IRRI $119 \times \mathrm{Bw}$ 363 cross. Bw 363 is a high yielding and locally well adapted variety which is tolerant to iron toxicity. $F_{1}$ and $F_{2}$ progenies of IRRI $119 \times$ Bw363 cross were developed at RARDC, Bombuwela.

\section{Phenotypic screening for submergence tolerance}

Fourteen day old seedlings of $F_{2}$ progenies, submergence tolerant rice varieties (SwarnaSub-1, IR64-Sub-1, IRRI 119, Samba MashuriSub-1 and Goda heenati) and submergence intolerant local rice varieties (Bg 360, Bg 94-1 and $\mathrm{Bw} 363)$ were grown in pots $(\mathrm{n}=15)$ and submerged for 14 days in a tank having a $60 \mathrm{~cm}$ deep water column (from soil surface to water surface). The pots contained approximately 400 $\mathrm{g}$ of soil with no fertilizer. During the submergence period, the temperature of water in the tank and light intensity on the water surface were recorded. De-submerged plants were then given 14 days to recover. The total length of the longest leaf was taken as the height of the plant and was recorded before submergence and 14 days after submergence (i.e., immediately after de-submergence). Heights of plants of all examined rice varieties before and at 14 days of submergence were compared by using the Statistical Package for the Social Sciences (SPSS - Version 17.0) software.

Table 1. Score for submergence tolerance [modified after Suprihatno and Coffman (1981)]

Leaf morphology

Score

$\begin{array}{lc}\text { Erect dark green leaves, greater elongation, new leaf development } & 1 \\ \text { Erect green leaves, little elongation } & 2 \\ \text { Green leaves, little elongation } & 3 \\ \text { Droopy, pale green leaves, moderate elongation } & 4-6 \\ \text { Long, pale green leaves, elongated, few survived } & 7-8 \\ \text { Long brownish leaves, elongated, dead } & 9\end{array}$


Survival of plants following de-submergence was scored in terms of elongation of existing leaves, development of new leaves and colour of leaves at the end of submergence period, 7 and 14 days after de-submergence. Scoring was based on the modified Standard Evaluation System (SES), developed by Suprihatno and Coffman (1981) for rating submergence tolerance in rice (Table 1).

\section{DNA marker analysis}

DNA was extracted from young leaves of above mentioned submergence tolerant and susceptible rice varieties employing Dellaporta miniprep protocol (Dellaporta et al., 1985) to determine the specific allelic sizes of RM 464A and RM 219 microsatellite markers that are linked to Sub-1 locus.

PCR was performed in $50 \mu \mathrm{l}$ reaction volumes in Gene Amp PCR system 9600. PCR master mix was prepared by adding $2.5 \mu \mathrm{l}$ of $10 \times$ buffer containing $\mathrm{MgCl}_{2}$ (Promega), $0.5 \mu \mathrm{l}$ of $10 \mathrm{mM}$ dNTP, $1.65 \mu \mathrm{l}$ of each $5 \mu \mathrm{M}$ of forward and reverse primers, $16.4 \mu \mathrm{l}$ of water for injection and $0.3 \mu 1$ of $5 \mathrm{U} / \mu 1 \mathrm{Taq}$ DNA polymerase. These volumes were added in multiples according to the number of PCR tubes (samples) used in laboratory analyses. Two $\mu \mathrm{l}$ of DNA template was added to each tube and a PCR was performed according to the protocol for RM 464A and RM 219 primers. Initial denaturation for $5 \mathrm{~min}$ at $94{ }^{\circ} \mathrm{C}$, each cycle comprised $1 \mathrm{~min}$ denaturation at $94{ }^{\circ} \mathrm{C}, 1 \mathrm{~min}$ annealing at $59^{\circ} \mathrm{C}$, and 2 min extension at $72{ }^{\circ} \mathrm{C}$ with extension for $5 \mathrm{~min}$ at $72{ }^{\circ} \mathrm{C}$ at the end of 35 cycles.

The PCR amplification products were visualized in $2 \%$ agarose stained with ethidium bromide $(0.2 \mu \mathrm{g} / \mathrm{ml})$ using UV transilluminator. Polyacrylamide gel electrophoresis (6\%) was carried out to evaluate the allelic sizes of the RM 464A and RM 219 markers. CTT multiplex allelic ladder (THO1: $179 \mathrm{bp}-203 \mathrm{bp}$ and TPOX: 224 bp - 252 bp) was used to determine the allelic sizes of the RM 464A marker. Short tandem repeat (STR) ladder (D13: 165-197 bp and D7:215-247 bp) was used to determine the allelic sizes of the RM 219 marker.

\footnotetext{
Analysis of allelic sizes of RM 464A and RM 219 markers in $F_{1}(B w 363 \times$ IRRI 119) and $\mathbf{F}_{2}$ progenies

Tender leaves of $\mathrm{F}_{1}$ plants arising from a cross $\mathrm{Bw} 363$ and IRRI 119, and $\mathrm{F}_{2}$ plants that were recovered after the 14 days of submergence were used for DNA extraction and PCR amplification
}

with primers for RM 464A and RM 219. PCR products were analyzed using $6 \%$ polyacrylamide gel electrophoresis and specific alleles of these markers were determined using appropriate allelic ladder as stated above.

\section{RESULTS}

$\begin{aligned} & \text { Phenotypic } \\ & \text { tolerance }\end{aligned}$
$\begin{aligned} & \text { Acclimative } \\ & \text { submergence }\end{aligned}$

Submergence phenotype in rice was determined by evaluation of acclimative shoot response in both tolerant and susceptible rice varieties. Correct phenotyping is essential to establish and validate the DNA markers linked to $S u b-1$ locus which is responsible for submergence tolerance. Fourteen day old, submergence tolerant and susceptible rice varieties appeared similar in leaf morphology (plant height, shape of the leaf and colour) prior to submergence (Figure 2). During the submergence period, the water temperature of the tank varied from 28 to $30{ }^{\circ} \mathrm{C}$. The average light intensity on the water surface was 1067 $\mu \mathrm{mol} \mathrm{m} \mathrm{s}^{-1}$.

During 14 day submergence, $\mathrm{Bg}$ 360, Bg 94-1 and $\mathrm{Bw} 363$ showed a significance increase at $p<0.05$ in plant height when compared to that of submergence tolerant varieties. Goda heenati also showed similar acclimative shoot response as in submergence tolerant varieties (Figure 2). Leaves of susceptible varieties appeared spindly, chlorotic and elongated whereas leaves of submergence tolerant plants showed very little elongation and were fully green in colour.

\section{Evaluation of survival of plants after de- submergence}

Survival of plants after 7 and 14 days of desubmergence was used as an additional parameter to assess the submergence tolerance. Tolerant plants showed new shoot development and elongation of existing green shoots after desubmergence while shoots of susceptible varieties had a distinct appearance with browning and withering [Figures 3(a), and (b)]. Thus, survivability was significantly different in tolerant and susceptible varieties at both 7 and 14 days after de-submergence $(p<0.05)$. SwarnaSub-1, IR64-Sub-1 and IRRI 119 showed $100 \%$ survival at 14 days after de-submergence while Samba Mashuri-Sub-1 while Goda heenati showed $93.3 \%$ survivability (Table 2). 


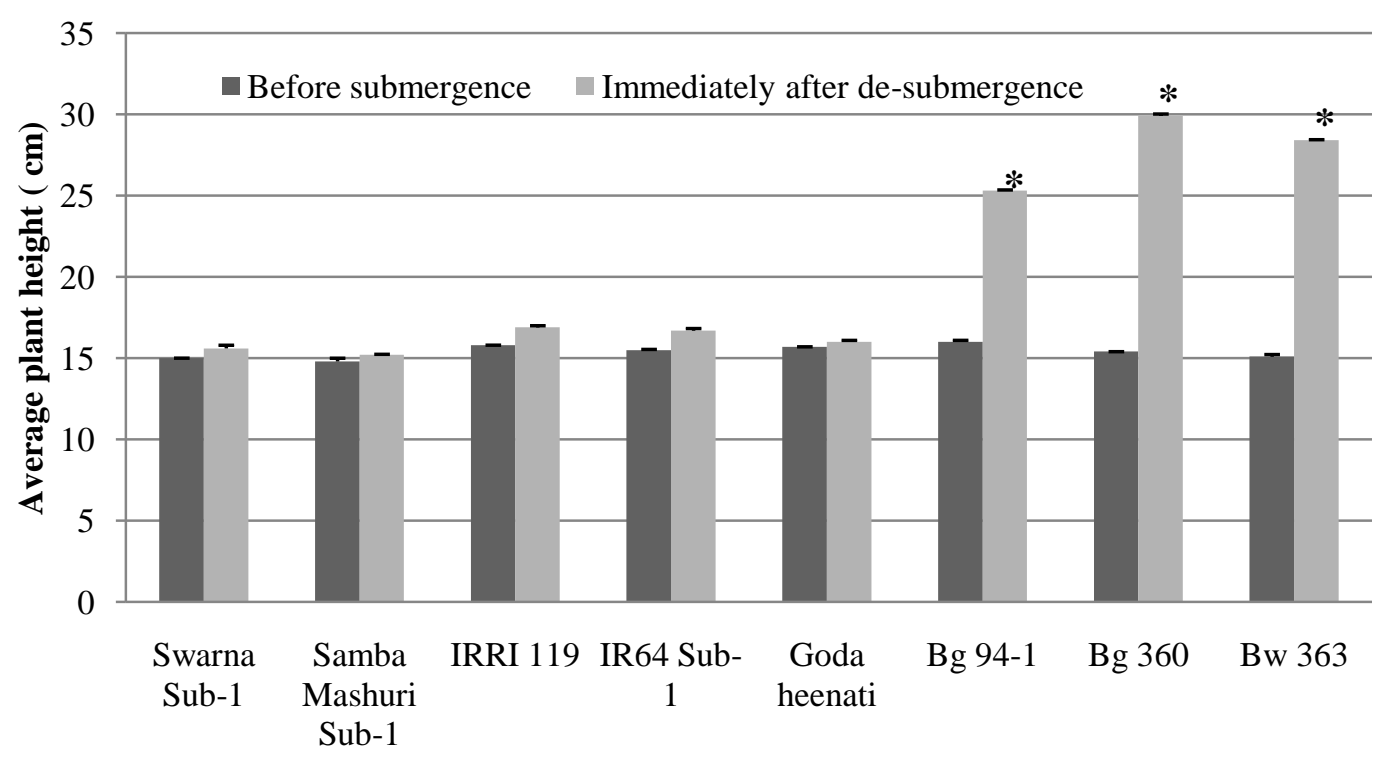

Figure 2. Average height of 14 day old seedlings before submergence and immediately after desubmergence with the standard error of means. The asterisks indicate the submergence susceptible plants with a significant height increase during submergence period $(p<0.05)$.

Table 2. Survival of submergence tolerant and susceptible varieties immediately after de-submergence, and at 7 and 14 days after de-submergence with respective submergence tolerance scores

\begin{tabular}{lcccc}
\hline \multicolumn{5}{c}{ Survival of plants $(\%)$} \\
Rice variety & \multicolumn{5}{c}{$\begin{array}{c}\text { Immediately after } \\
\text { de- submergence }\end{array}$} & $\begin{array}{c}\text { 7 days after } \\
\text { de-submergence }\end{array}$ & $\begin{array}{c}\text { 14 days after de- } \\
\text { submergence }\end{array}$ & $\begin{array}{c}\text { Submergence } \\
\text { tolerance score } \\
\text { as given in } \\
\text { Table 1 }\end{array}$ \\
\hline Swarna- Sub-1 & 100 & 100 & 100 & 1 \\
Samba Mashuri- Sub-1 & 93.3 & 93.3 & 93.3 & 1 \\
IR64-Sub-1 & 100 & 100 & 100 & 1 \\
IRRI 119 & 100 & 100 & 100 & 1 \\
Goda heenati & 93.3 & 93.3 & 93.3 & 1 \\
Bg 94-1 & 53.3 & 26.6 & 0.0 & 9 \\
Bg 360 & 66.6 & 20.0 & 0.0 & 9 \\
Bw 363 & 73.3 & 20.0 & 0.0 & 9 \\
\hline
\end{tabular}

Table 3. Allelic sizes of RM 464A and RM 219 markers with the submergence tolerance score for IRRI 119 and $\mathrm{Bw} 363$ which were two parents of the $\mathrm{F}_{1}$ progeny

\begin{tabular}{lccc}
\hline Variety & $\begin{array}{c}\text { Alleles of } \\
\text { RM 464A (bp) }\end{array}$ & $\begin{array}{c}\text { Alleles of } \\
\text { RM 219 (bp) }\end{array}$ & $\begin{array}{c}\text { Submergence } \\
\text { tolerance score }\end{array}$ \\
\hline IRRI 119 & 226 & 220 & 1 \\
Bw 363 & 231 & 190 & 9 \\
\hline
\end{tabular}


Table 4. Allelic sizes of RM 464A and RM 219 markers with submergence tolerance score for some selected submergence tolerant and susceptible varieties

\begin{tabular}{lccc}
\hline \multicolumn{1}{c}{ Rice variety } & $\begin{array}{c}\text { Alleles of } \\
\text { RM 464A (bp) }\end{array}$ & $\begin{array}{c}\text { Alleles of } \\
\text { RM 219 (bp) }\end{array}$ & $\begin{array}{c}\text { Submergence } \\
\text { tolerance score }\end{array}$ \\
\hline Swarna- Sub-1 & 226 & 190 & 1 \\
Samba Mashuri- Sub-1 & 226 & 220 & 1 \\
IR64-Sub-1 & 226 & 220 & 1 \\
Goda heenati & 226 & 214 & 1 \\
Bg 360 & 226 & 214 & 9 \\
Bg 94-1 & 226 & 230 & 9 \\
\hline
\end{tabular}

After 7 days of de-submergence, $\mathrm{Bg} 94-1, \mathrm{Bg}$ 360 and $\mathrm{Bw} 363$ showed 26.6\%, 20.0\% and $20.0 \%$ survival while the susceptible plants had turned brown and withered [Figure 3(a) and (b); Table 2]. All susceptible plants were dead by 14 days after de-submergence and hence scored 9 in the submergence tolerance scale but submergence tolerant varieties displayed a score of 1 .

Evaluation of allelic variability of the RM 464A and RM 219 in IRRI 119, Bw 363 (parents) and selected submergence tolerant and susceptible rice varieties

The association of specific alleles of RM 464A and RM 219 markers that are known to be linked to $S u b-1$ which expresses submergence tolerance was achieved by determining the specific allele sizes of the two markers and by correlating them with the respective submergence tolerance scores in the concerned rice varieties. Annealing temperature of $59{ }^{\circ} \mathrm{C}$ yielded optimized amplification for RM 464A and RM 219 markers and amplified products were size separated on $6 \%$ polyacrylamide gels to determine the specific allele sizes.

Evaluation of allelic variability of the RM 464A and RM 219 in IRRI 119, Bw 363 (parents) and selected submergence tolerant and susceptible rice varieties

The association of specific alleles of RM 464A and RM 219 markers that are known to be linked to $S u b-1$ which expresses submergence tolerance was achieved by determining the specific allele sizes of the two markers and by correlating them with the respective submergence tolerance scores in the concerned rice varieties. Annealing temperature of $59{ }^{\circ} \mathrm{C}$ yielded optimized amplification for RM 464A and RM 219 markers and amplified products were size separated on $6 \%$ polyacrylamide gels to determine the specific allele sizes.

PCR amplification products of two markers RM 464A and RM 219 were analyzed in the two parents of IRRI 119 (Sub-1 donor) $\times$ Bw 363 cross. With a submergence tolerance score of 1 IRRI 119 yielded a 226 bp allele for RM 464A while RM 219 amplicon was 220 bp. Bw 363 with submergence tolerance score of 9 yielded a 231 bp allele for RM 464A and RM 219 amplicon was 190 bp (Table 3). This revealed the homozygous state of these two markers in the two parents.

Further, in order to determine the usefulness of the two markers for selection of $S u b-1$ for breeding of submergence tolerance in local rice varieties, submergence tolerance enhanced varieties (Swarna-Sub-1, Samba Mashuri-Sub-1, IR64-Sub-1), submergence tolerant land race; Goda heenati and submergence susceptible rice varieties ( $\mathrm{Bg} 360$ and $\mathrm{Bg}$ 94-1) were assayed with RM 464A and RM 219 markers.

The RM 464A amplicons from Swarna-Sub-1, Samba Mashuri-Sub-1, IR64-Sub-1, Goda heenati, Bg 360 and $\mathrm{Bg}$ 94-1 were 226 bp in length (Table 4). However, as noted earlier, the only exception was Bw 363 which gave a $231 \mathrm{bp}$ allele (Table 3 ). These amplicons are within the 224-231 bp range of RM 464A PCR amplified from 55 diverse japonica and indica rice accessions (Xu et al., 2004). Higher allelic variability for RM 219 marker was observed among the varieties tested. Samba Mashuri-Sub1, IR64-Sub-1 including IRRI 119 had an allele of 220 bp while Swarna-Sub-1 had a 190 bp allele (Tables 3 and 4). 

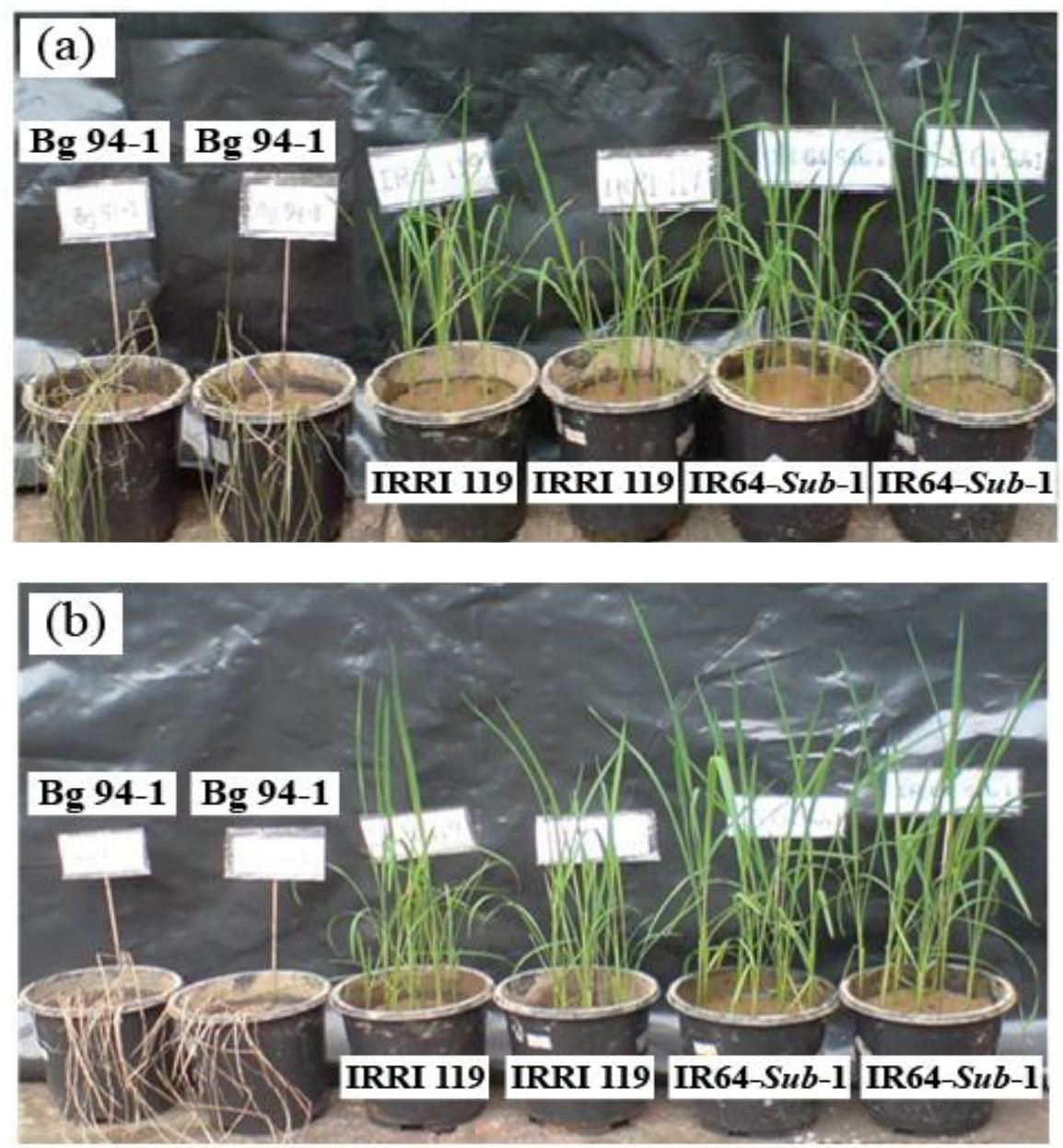

Figure 3. Some submergence tolerant (IRRI 119 and IR64-Sub-1) and submergence susceptible (Bg 94-1) rice varieties after (a) 7 days and (b) 14 days of de-submergence following 14 days of submergence.

(a)

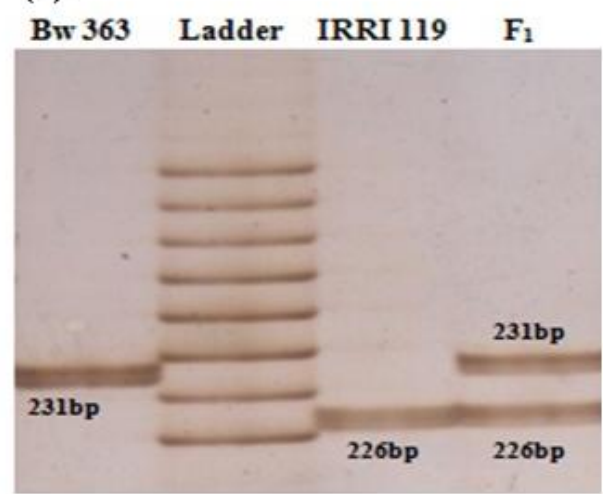

(b)

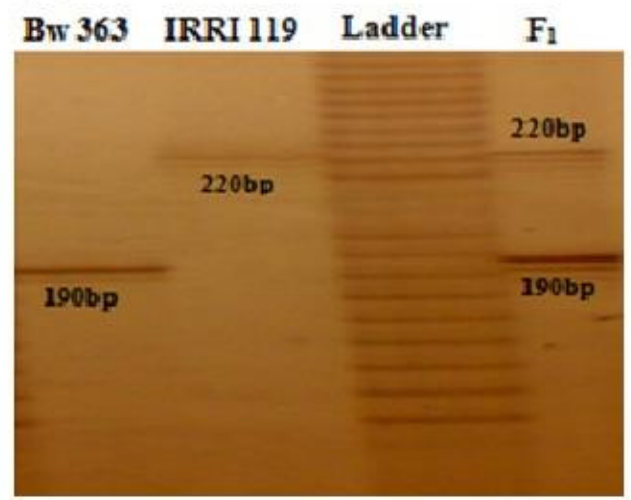

Figure 4. (a) Polyacrylamide gel electrophoresis profiles of PCR amplicons of RM 464A and (b) RM 219 for IRRI 119, Bw 363 and $F_{1}$ Genomic DNA of $F_{1}$ plant derived from across between submergence tolerant IRRI 119 and submergence susceptible variety Bw 363 was amplified with RM 464A and RM 219 separately. Amplified samples were analyzed on $6 \%$ polyacrylamide gels. 
Goda heenati displayed 2 distinct bands at 215 bp. As shown in Figure 4(b), for Bw 363 and IRRI 119 varieties, secondary bands were observed for RM 219. This is probably due to stuttering effect that occurred during PCR amplification. Determination of allele size for RM 219 was based on the most intense band. Allele sizes determined for all the varieties with the exception of Bg 94-1 for RM 219 were within 190-224 bp range of RM 219 amplicons detected for 55 diverse japonica and indica accessions (Xu et al., 2004). Bg 94-1 had an allele of $230 \mathrm{bp}$ for RM 219.

There was no polymorphism evident for RM464A marker amongst tested submergence tolerant and susceptible varieties, with the exception of $\mathrm{Bw} 363$. However, polymorphism was evident for RM 219 (Tables 3 and 4). This analysis also showed that both RM 464A and RM 219 could be employed as useful, easily scorable DNA markers for selection during introduction of $S u b-1$ locus from submergence tolerance enhanced variety IRRI 119 to local rice variety Bw 363 .

\section{Use of RM 464A and RM 219 markers in the analysis of $F_{1}$ (IRRI $119 \times B w 363$ ) and $F_{2}$ progenies \\ RM 464A and RM 219 markers were utilized to analyze $F_{1}$ progeny resulted from the cross between IRRI $119 \times \mathrm{Bw} 363$ and $\mathrm{F}_{2}$ progeny.}

IRRI 119 RM 464A displayed a 226 bp allele while a 220 bp allele for RM 219 was present. Bw 363 yielded a 231 bp allele for RM 464A and $190 \mathrm{bp}$ allele for RM 219 marker. These two markers were homozygous in the parents as previously observed. $F_{1}$ progeny displayed 226 bp and 231 bp alleles for RM 464A marker and $190 \mathrm{bp}$ and $220 \mathrm{bp}$ for RM 219, the heterozygous state for both markers [Figures $4(a)$ and $(b)] . \mathrm{F}_{1}$ was allowed to self pollinate to produce $\mathrm{F}_{2}$ without undertaking phenotypic selection.

The phenotypic evaluation of submergence tolerance and genotype of RM 464A and RM 219 markers of 15 plants in the $F_{2}$ progeny was conducted [Figures 5(a) and 5(b)]. Out of these, nine $F_{2}$ plants demonstrated submergence tolerance phenotype during submergence and desubmergence. Analysis of RM 464A and RM 219 markers revealed that all these nine plants were heterozygous for both markers.

The presence of specific alleles (226 bp) of RM
464A and 220 bp allele of RM 219 linked to Sub-1 locus in IRRI 119 was evident. All nine $\mathrm{F}_{2}$ plants during complete submergence over 14 days showed the same acclimative shoot response as observed for submergence tolerant variety IRRI 119 ( $S u b-1$ donor parent used for this cross). They also expressed $100 \%$ survivability at the end of the 14 day desubmergence period and were assigned submergence tolerance score 1 .

Remaining six $\mathrm{F}_{2}$ plants were homozygous for both markers and had $231 \mathrm{bp}$ allele of RM 464A marker and $190 \mathrm{bp}$ allele of RM 219 marker. Both these alleles, as earlier determined, are not linked to Sub-1 locus of IRRI 119. These $6 \mathrm{~F}_{2}$ plants displayed acclimative shoot response similar to submergence susceptible parent $\mathrm{Bw}$ 363, while zero percentage survivability was observed at the end of 14 day de-submergence period and the lowest submergence tolerance score of 9 was assigned. It was clear that $226 \mathrm{bp}$ allele of RM 464A marker and 220 bp allele of RM 219 marker were able to reliably distinguish all submergence tolerant $F_{2}$ plants from susceptible plants.

\section{DISCUSSION}

Mapping and molecular characterization of Sub1 has led to greater understanding of the molecular mechanism underlying submergence tolerance at the Sub-1 locus (Fukao et al., 2006) as well as the identification of gene based or tightly linked DNA markers leading to reliable and precise genotyping (Siangliw et al., 2003; $\mathrm{Xu}$ et al., 2004). As a result of genetic linkage, DNA markers can be used to detect allelic variations in the genes responsible for important traits. By using DNA markers to assist in plant breeding, efficiency and precision of transfer of specific allele from a donor line to recipient line can be greatly increased (Collard and Mackill, 2008). The uses of DNA markers increase the speed of the selection process at each generation, which increase the efficiency.

The main objective of the work reported here was to employ DNA marker assisted selection to initiate breeding of $S u b-1$ from submergence tolerance enhanced variety such as IRRI 119 in to a local rice variety Bw 363. In this effort it was essential to establish a robust procedure to identify tightly linked DNA markers to reliably predict submergence tolerance phenotype. 
(a)

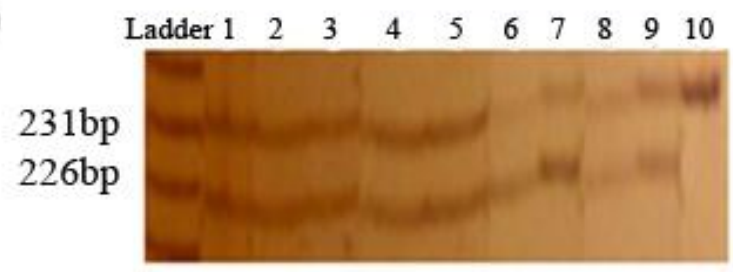

(b)

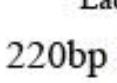

$190 \mathrm{bp}$

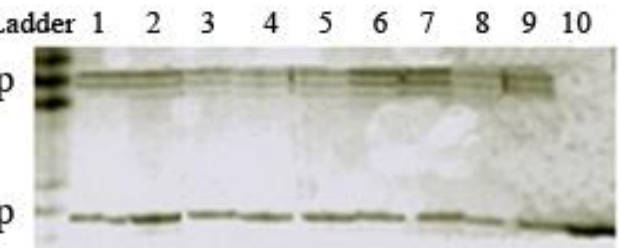

Figure 5. Polyacrylamide gel electrophoresis profiles of PCR amplicons of (a) RM 464A and (b) RM 219 for $F_{2}$ plants. Genomic DNA of $F_{2}$ plants recovered from submergence tolerance plants was amplified with RM 464A and RM 219 separately. Amplified samples were analyzed on 6\% polyacrylamide gels. (Lanes 1, $2,3,4,5,6,7,8$ and 9: tolerant $\mathrm{F}_{2}$ plants; lane 10: dead $\mathrm{F}_{2}$ plants).

P:

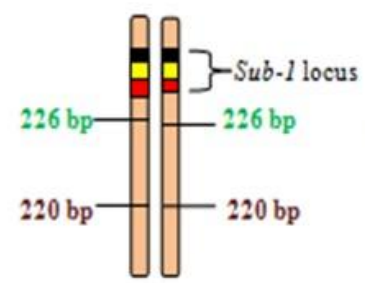

IRRI 119 (Sub-1 donor)

Submergence Tolerant

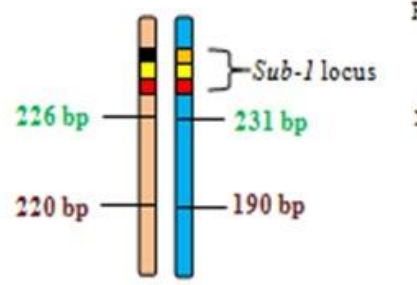

F:

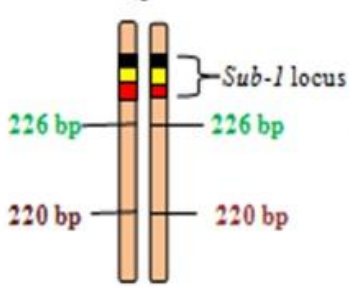

Submergence Tolerant $p$

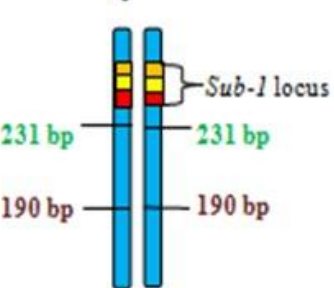

Bw 363

Susceptible Variety

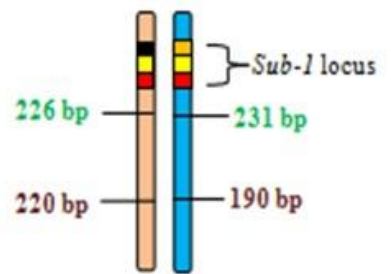

Figure 6. Graphical representation of position of Sub-1 locus and allele of RM 219 and RM 464A DNA markers in IRRI $119\left(\mathrm{P}_{1}\right)$, Bw $363\left(\mathrm{P}_{2}\right), \mathrm{F}_{1}$, and $\mathrm{F}_{2}$ progenies (Recombinants of the $\mathrm{F}_{2}$ progeny were not considered in this graphical representation). Genes (Subl B, Subl C genes, and Subl A-1 allele which is responsible for submergence tolerance in rice and Subl A-2 allele of Subl A) contained within $S u b-1$ for IRRI 119 and Bw 363 are indicated (adopted from Xu et al., 2006) as follows; $\square$ Subl B, $\square$ Subl C, $\square$ Sub1 A-2 (Susceptible), - Sub1 A-1 (Tolerant). Allele sizes of the markers are indicated by following colours; $\square$ RM 219 and $\square$ RM 464A 
In the initial phase, evaluation of submergence tolerance during the 14 day submergence and 14 day de-submergence periods in known tolerant and selected susceptible varieties was carried out.

Accurate phenotyping of submergence tolerance in tolerant and susceptible rice varieties was assessed by evaluating the acclimative shoot response during 14 day submergence period and by determining the survivability during 14 day de-submergence period. Acclimative shoot response to complete submergence in nonaquatic plants is species and genotype specific (Fukao and Serres, 2004). In lowland rice, submergence tolerance controlled by Sub-1 imposes quiescence that restricts leaf elongation and leaf development during submergence. This allows shoot re-growth and leaf development to re-commence upon de-submergence. This distinctive quiescence response strategy displayed by $S u b-1$ controlling submergence tolerance is clearly absent in submergence susceptible rice varieties. A delicate balance between energy conservation during quiescence rather than mere energy consumption is believed to be the mechanism that underlies submergence tolerance (Serres et al., 2010).

All submergence susceptible rice varieties $(\mathrm{Bg}$ 94-1, Bg 360 and Bw 363) showed increased leaf elongation during the 14 day submergence period, while all $S u b-1$ containing varieties and Goda heenati displayed restricted leaf elongation akin to acclimative shoot response observed during quiescence period reported for submergence tolerant rice (Fukao and Serres, 2004). Upon de-submergence, within 14 days all susceptible varieties perished $(0 \%$ survivability) with the lowest submergence tolerance score of 9. In contrast, all Sub-1 containing rice varieties and Goda heenati showed recommencement of shoot elongation and development of new shoot during desubmergence, with approximately $100 \%$ survivability and submergence tolerance scores of 1 . It is evident that accurate phenotyping of submergence tolerance in rice in this study was possible by assessing acclimative shoot response during submergence along with determination of survivability and assigning submergence tolerance scores to respective rice varieties during the 14 day de-submergence period.

Previously shown tight linkage of RM 464A and RM 219 DNA markers to $S u b-1$ led us to believe that these markers could be employed to monitor introgression of Sub-1 from a donor parent to a local rice variety. During marker validation phase, accurate phenotyping and subsequent correlation of polymorphic DNA bands of RM 464A and RM 219 markers to submergence tolerance led to the identification of specific marker alleles associated with submergence tolerance and the susceptible trait in the rice varieties used in this study.

Alleles detected for RM 464A and RM 219 in this study appear to be of similar size to RM 464A and RM 219 alleles reported for 55 diverse japonica and indica rice accessions. Therefore, the amplified fragments with RM 464A and RM 219 primers in the present study could be considered to be the same as those referred to in $\mathrm{Xu}$ et al., 2004. The RM 464A allele from IRRI 119 (Sub-1 donor parent) and Bw 363 were 226 bp and 231 bp (Figure 4A) respectively. The RM 219 displayed a $220 \mathrm{bp}$ allele for IRRI 119 and a $190 \mathrm{bp}$ allele for Bw 363 (Figure 4b). Therefore, the polymorphism of RM 464A and RM 219 detected between IRRI 119 ( $S u b-1$ donor) and Bw 363 revealed that these two markers could be useful to monitor the target locus $S u b-1$ in a cross between IRRI 119 and Bw 363.

Graphical representation of tightly linked marker alleles of RM 464A and RM 219 with $S u b-1$ in submergence tolerant parent IRRI 119 and the respective marker alleles that correspond to submergence susceptible parent $\mathrm{Bw} 363$ is shown in Figure 6 (possible recombination events between Sub-1 and RM 464A \& RM 219 markers in $\mathrm{F}_{2}$ progeny were not considered for this Figure). It reveals that haplotype of $226 \mathrm{bp}$ allele of RM 464A and 220 bp allele of RM 219 is sufficient to monitor $S u b-1$ locus in IRRI 119 , $\mathrm{F}_{1}$, and $\mathrm{F}_{2}$ progenies. The $S u b-1$ locus in IRRI 119 and the $F_{2}$ progeny conferred submergence tolerance as indicated by the submergence tolerance score of 1 . Further, it demonstrates that haplotype of $231 \mathrm{bp}$ allele of RM 464A and 190 bp allele of RM 219 identified submergence susceptibility in $\mathrm{Bw} 363\left(\mathrm{P}_{2}\right)$ and in $\mathrm{F}_{2}$ progeny which expressed a submergence tolerance score of 9. This analysis shows that the haplotype (linked marker alleles) of $226 \mathrm{bp}$ allele of RM 464A and 220 bp allele of RM 219 could be employed as diagnostic markers to distinguish and select submergence tolerant individuals from susceptible ones to advance to $F_{3}$, without being subject to laborious phenotyping.

The two DNA markers RM 464A and RM 219 used in this study produced easily scorable polymorphic bands that could reliably predict submergence tolerance expressed by $S u b-1$. If 
sufficient polymorphism exists between the $S u b$ 1 donor parent and the selected recipient parent with respect to these two markers, they could be employed successfully to introgress $S u b-1$ controlled submergence tolerance into other susceptible local rice varieties in breeding programmes. The RM 464A and RM 219 DNA markers have been used successfully to select Sub-1 expressed submergence tolerance in another rice breeding programme involving submergence tolerance donor derived from IR 40931-26 indica line and recipient temperate japonica cultivar M 202 (Xu et al., 2004).

Development of submergence tolerant rice from local rice germplasm via the use of DNA markers to assist selection in rice breeding allows the breeders to circumvent several inherent problems associated with conventional rice breeding, especially those involving cumbersome and time consuming submergence tolerance phenotypic screening. This approach appears to be the most precise, efficient strategy to breed submergence tolerant local rice varieties that could minimize submergence damage in rice crop and improve productivity during unexpected floods.

\section{CONCLUSIONS}

The current study initiated DNA marker assisted breeding to incorporate submergence tolerance trait controlled by $S u b-1$, a major QTL. The haplotype of $226 \mathrm{bp}$ allele of DNA marker RM 464A and 220 bp allele of RM 219 which are known to be linked to the target locus $S u b-1$ was sufficient to select submergence tolerant individuals from the submergence susceptible individuals that resulted from a cross between Sub-1 donor parent IRRI 119 and locally well adapted variety $\mathrm{Bw} 363$. At present, further improvement of these plants is being conducted and later generations are being monitored. These plants can serve as useful material to produce a rice variety with superior agronomic attributes of Bw 363 along with tolerance to submergence.

\section{REFERENCES}

Collard B. C. Y. and Mackill, D. J. (2008). Marker-assisted selection: an approach for precision plant breeding in the twenty-first century. Physiological transactions of the Royal Society 363: 557-572.

Dellaporta S. L., Wood J. and Hicks, J. B. (1985). Maize DNA minipreparation: version II. Plant Mol Biol. Rep. 1: 19-21. Molecular
Biology of Plants: a laboratory course manual (Eds. R. Malmberg, J. Messing \& I.S Sussex). (pp. 363). Cold Spring Harbor Laboratory Press, Cold Spring Harbor, NY.

Fukao, T., Harris, T. and Serres, J. B. (2008). Evolutionary analysis of the Sub1 gene cluster that confers submergence tolerance to domesticated rice. Annals of Botany 103:143-150.

Fukao, T. and Serres, J. B. (2004). Plant responses to hypoxia - is survival a balancing act? Trends Plant Science 9: 449-456.

Fukao, T. and Serres, J. B. (2008). Ethylene-A key regulator of submergence responses in rice. Plant Science 175: 43-51.

Fukao, T., Xu K., Ronald, P. C. and Serre J. B. (2006). A variable cluster of ethylene response factor-like genes regulates metabolic and developmental acclimation responses to submergence in rice. The Plant Cell 18: 2021-2034.

Jena, K. K. and Mackill, D. J. (2008). Molecular markers and their use in marker assisted selection in rice. Crop Science 48:12661276.

IRRI (2007). Superior germplasm and management options to overcome submergence stress developed by 2012. International Rice Research Institute, Los Banos, Philipines.

Neeraja, C. N., Rodriguez, R. M., Pamplona, A., Heuer, S., Collard, B. C. Y., Septiningsih, E. M., Vergara, G., Sanchez, D., Xu, K., Ismail, A.M. and Mackill, D. J. (2007). A marker-assisted backcross approach for developing submergence -tolerant rice cultivars. Theoretical and Applied Genetics 115: 767-776.

Serres, J. B., Fukao, T., Ronald, P., Ismail, A., Heuer, S. and Mackill D. (2010). Submergence tolerant rice: Subl's journey from landrace to modern cultivar. Rice 3:138-147.

Setter, T. L ., Ellis, M., Laureles, E. V., Ella, E. S., Senadhira, D., Mishra, S. B., Sarkarung, S. and Datta, S. (1997). Physiology and genetics of submergence tolerance in rice. Annals of Botany 79: 67-77.

Siangliw, M., Toojinda, T., Tragoonrung, S. and Vanarichit, A. (2003). Thai Jasmine rice carrying QTLch9 (SubQTL) in submergence tolerant. Annals of Botany 91: 255-261.

Suprihatno, B. and Coffman, W. R. (1981). Inheritance of submergence tolerance of rice (Oryza sativa L.) Sabrao Journal 13:98-108.

Toojinda, T., Siangliw, M., Tragoonrung, S. and Vanavichit, A. (2003). Molecular genetics of 
submergence tolerance in rice: QTL analysis of key traits. Annals of Botany 91: 243-253.

$\mathrm{Xu}, \mathrm{K}$., Deb, R. and Mackill D. J. (2004). A microsatellite marker and a codominant PCR-based marker for marker-assisted selection of submergence tolerance in rice. Crop Science 44:248-253.

Xu, K. and Mackill D. J. (1996). A major locus for submergence tolerance mapped on rice chromosome 9. Molecular Breeding 2: 219224.
$\mathrm{Xu}, \quad \mathrm{K}$, Xu, X., Fukao, T., Canlas, P., Rodriguez, R. M., Heuer, S., Ismail, A. M., Serres, J. B., Ronald, P. C., and Mackill D. J. (2006). Sub1A is an ethylene-responsefactor-like gene that confers submergence tolerance to rice. Nature 442: 705-708.

FAO country report (2011). Sri Lanka: Global information and early warning system on food and agriculture. Food and Agriculture Organization, Rome, Italy. Available at http://www.fao.org/giews/countrybrief/count ry.jsp?code=LKA (02 February 2012). 